\title{
DISPERSÃO DE SEMENTES DE URUVALHEIRA (Platypodium elegans VOG.) (Fabaceae) EM UM CERRADÃO, UBERLÂNDIA-MG ${ }^{1}$
}

\author{
Sérgio de Faria Lopes², Ana Paula de Oliveira², Sharon Borges Neves² e Ivan Schiavini ${ }^{3}$ \\ RESUMO - Estudou-se a dispersão de sementes de cinco árvores-matriz de Platypodium elegans Vog. (Fabaceae) \\ em área de cerradão, na Estação Ecológica do Panga (EEP). As amostragens foram feitas em parcelas de 0,25 m2, \\ posicionadas em linhas partindo da base da matriz em direção aos quatro pontos cardeais (Norte, Sul, Leste \\ e Oeste), marcadas a cada metro. No laboratório, os frutos foram abertos para análise da qualidade das sementes. \\ Foram amostradas 1.131 sementes, das quais 18,4\% estavam intactas e 81,6\%, danificadas e provavelmente \\ inviáveis para germinação. A dispersão das sementes sofreu influência da topografia do local das matrizes, \\ das respostas fisiológicas e genéticas à pré-dispersão, bem como do possível direcionamento favorável do \\ vento. Dessa forma, a atuação conjunta desses fatores funcionaria como facilitadores relevantes na formação \\ do banco de sementes e moldaria a probabilidade de estabelecimento de novos indivíduos, tanto na área estudada \\ quanto nas fisionomias adjacentes..
}

Palavras-chave: Cerradão, Platypodium elegans e Dispersão.

\section{SEEDS DISPERSAL OF URUVALHEIRA (Platypodium elegans VOG.) (Fabaceae) IN CERRADÃO, UBERLANDIA, MG}

\begin{abstract}
It was studied seeds dispersal of five first trees of Platypodium elegans Vog. (Fabaceae), in area of cerradão in the Estação Ecológica do Panga (EEP). The samplings had been made in 0,25 plots of $\mathrm{m} 2$, located in lines leaving of the base of the matrix in direction to the four points cardinals (north, south, east and west), marked to each meter. The fruits had been opened for analysis of the quality of the seeds. A total of 1.131 seeds was collected in the sampling area of the five arrays, of which 18,4\% they were viable and 81,6\% probably impracticable for germination. The dispersion of the seeds suffered influence from the topography of the place of the matrices, of the physiological and genetic answers daily early-dispersion, as well as of the possible favorable aiming of the wind. The joint action of these factors serves as relevant facilitators on the seed bank training as so as the probability of establishment of new individuals both in the studied area and also in adjacent vegetation.
\end{abstract}

Keywords: Cerradão, Platypodium elegans and Dispersion

\section{INTRODUÇÃO}

A dispersão de sementes de espécies arbóreas tem relação direta com a dinâmica da floresta tropical. Harper (1977) caracterizou essa importância ao afirmar que o tamanho das populações é mais afetado pela dispersão de sementes do que pelo número de espécies na comunidade. O fluxo de sementes num hábitat é o principal determinante do potencial de estabelecimento de dada população naquele local. Dessa forma, as espécies vegetais utilizam-se de diversos mecanismos para terem suas sementes transportadas a partir da planta-mãe. Seja qual for o mecanismo, isso resulta na distribuição de sementes no meio ambiente, geralmente com alta densidade perto dos indivíduos parentais. Esta distribuição é chamada de "sombra de sementes" e pode ser determinada através de medidas da densidade de sementes, em relação ao distanciamento crescente do indivíduo-fonte (VAN DER PIJL, 1972). Os vetores de dispersão podem ser abióticos (vento, água, gravidade) ou bióticos (animais de grupos variados)

\footnotetext{
${ }^{1}$ Recebido em 03.12.2007 e aceito para publicação em 02.03.2010.

2 Programa de Pós-Graduação em Ciência Florestal pela Universidade Federal de Uberlândia, UFU, Brasil. E-mail: <slopeserginho@yahoo.com.br>.

${ }^{3}$ Universidade Federal de Uberlândia, UFU, Brasil.
} 
(STILES, 1989). Em relação aos vetores abióticos, as sementes, ou frutos anemocóricos, são caracterizados por adaptações morfológicas específicas, tornando-se passíveis de serem transportados pelo vento (AUGSPURGER, 1986).

Nessa perspectiva, as espécies anemocóricas, por não estarem sujeitas à competição por agentes dispersores na época de produção e dispersão de seus frutos, apresentariam maior sincronia com condições abióticas (MORELLATO e LEITÃO-FILHO, 1992). Em plantas anemocóricas, a baixa precipitação e a queda de folhas de muitas espécies na estação seca, seu caráter decíduo ou semidecíduo e sua posição na estratificação, somados aos ventos, em geral mais fortes nesse período, propiciariam melhor dispersão dos diásporos (MORELLATO et al., 1989).

De acordo com Daubenmire (1982), o vento é o agente de dispersão mais eficaz, e quanto mais alta a árvore e mais lenta a queda dos propágulos, maior a eficiência da dispersão. A anemocoria está geralmente associada às espécies pioneiras (JANZEN, 1988), aos ambientes secos e/ou sazonais (FRANKIE et al., 1974) e às áreas de vegetação mais abertas (HOWE e SMALLWOOD, 1982; DREZNER et al., 2001).

Assim, a dispersão geralmente é vista como uma adaptação para aumentar a probabilidade de sobrevivência, em que os principais fatores responsáveis pela mortalidade das plântulas são a densidade, a distância, ou ambas, em relação à planta-mãe. A dispersão também aumenta a probabilidade de sobrevivência dos novos indivíduos estabelecidos, movendo as sementes para locais desocupados ou hábitats mais satisfatórios (JANZEN, 1970, 1971; HUBBELL, 1980; LEVEY e BYRNE, 1993).

Platypodium elegans Vog (Fabaceae) é uma espécie de ocorrência natural no Cerrado e em zonas de transição Cerrado-Floresta. Encontrada em terrenos bem drenados (LORENZI, 2002), sua madeira é empregada na carpintaria e marcenaria. Além disso, a espécie apresenta potencial ornamental, fornecendo madeira clara, sem cerne e pouco resistente ao tempo, porém dura e difícil de ser rachada (ALMEIDA et al., 1998); É muito utilizada para recomposição de áreas degradadas, com plantio em grandes áreas verdes e em sistemas agroflorestais (SCHORR et al., 2002).

Dessa forma, este trabalho teve como objetivo analisar a distribuição espacial de sementes de Platypodium elegans Vog. (Fabaceae) em uma área de cerradão da Estação Ecológica do Panga, em Uberlândia, MG, visando à ampliação do conhecimento da ecologia da espécie, bem como responder a algumas questões envolvidas: a) o número de sementes diminui em relação à distância da planta-mãe? b) Existe alguma direção predominante na dispersão das sementes e essa pode estar relacionada com alguma influência abiótica? c) Qual seria a probabilidade de estabelecimento das sementes dispersadas após pressões seletivas? Buscou-se responder a essas questões tendo em vista a hipótese prevista inicialmente por Janzen (1970), em que a maior parte das sementes seria dispersa próxima à matriz, diminuindo essa proporção à medida que se afastava da área de projeção da copa. O inverso ocorreria com a chance de escapar da predação dessas sementes, a qual seria maior quanto mais afastada estivesse da planta-mãe. Assim, o ótimo de estabelecimento de novos indivíduos da espécie ocorreria em meia distância entre a matriz e o máximo de distância da dispersão.

\section{MATERIAL E MÉTODOS}

\section{1. Área de estudo}

O estudo foi realizado na Estação Ecológica do Panga (EEP), uma Reserva Particular do Patrimônio Natural (RPPN) pertencente à Universidade Federal de Uberlândia, localizada na cidade de Uberlândia, MG. A EEP possuí a extensão de 409,5 ha e estava localizada a cerca de $30 \mathrm{~km}$ do centro da cidade, com as coordenadas geográficas $19^{\circ} 11^{\prime} 10^{\prime \prime}-19^{\circ} 09^{\prime} 20^{\prime \prime}$ de latitude sul e $48^{\circ}$ 23’20" - 48'24'35" de longitude oeste, a uma altitude de cerca de $800 \mathrm{~m}$ acima do nível do mar (SCHIAVINI e ARAÚJO, 1989). Na EEP, encontrou-se um gradiente florestal formado por um cerradão (área de estudo), Floresta Estacional Semidecídua e a Mata de Galeria. O cerradão apresentava altura média das árvores do dossel entre 8 e $15 \mathrm{~m}$, com estrato arbóreo predominantemente contínuo e cobertura arbórea de 50 a 90\% (RIBEIRO e WALTER, 1998).

A região apresenta clima do tipo Aw (KÖPPEN, 1948), marcado por uma sazonalidade com verão quente e úmido e inverno frio e seco (ROSA et al., 1991). Segundo dados meteorológicos da região, o período de maior precipitação está relacionado com o período mais quente (novembro a março), seguido por um período de quatro a cinco meses secos e mais frios. A temperatura média anual e a umidade relativa do ar não sofrem grandes oscilações durante todo o ano, exceto durante a estação 
seca, quando alguns registros locais apontam a umidade relativa do ar com valores de até 30\% durante o dia (ROSA et al., 1991).

\subsection{Espécie estudada}

Platypodium elegans Vog. (Fabaceae), conhecido como uruvalheira ou jacarandá-canzil, é uma arvore semidecídua, heliófita e característica do Cerrado localizado em terrenos bem drenados e em sua transição com florestas semideciduais. Os indivíduos adultos medem de 8 a $15 \mathrm{~m}$ de altura e possuem tronco com 40-50 cm de diâmetro. Apresenta dispersão uniforme e geralmente em alta frequência, floresce a partir de meados de setembro até novembro (ALMEIDA et al., 1998).

Os frutos amadurecem nos meses de setembro e outubro do ano seguinte (LORENZI, 2002). O fruto é uma sâmara, oblongo-obovada, lenhosa e com asa coriácea (RIZZINI, 1971), com a semente localizada na porção terminal (AUGSPURGER, 1989) e, quando secas, apresentam cor pardo-amarelada. O peso seco de uma sâmara é em média de 2 g, e o comprimento de sua ala é de aproximadamente $10 \mathrm{~cm}$ (AUGSPURGER, 1983). As sementes são atacadas por coleópteros do gênero Spermophago (ALMEIDA et al., 1998).

\subsection{Coleta e análise dos dados}

Para este estudo foram escolhidas cinco matrizes, relativamente distantes entre si, que apresentavam grande quantidade de frutos já dispersos sob e próximos à sua copa. Para cada matriz foram estendidas linhas a partir do tronco em direção aos quatro pontos cardeais (Norte, Sul, Leste e Oeste), com marcações em espaços de $1 \mathrm{~m}$, sobre as quais foram feitas amostragens. Essas linhas prolongavam-se até para a área fora da projeção da copa. Em cada distância de $1 \mathrm{~m}$, foram aplicadas duas unidades amostrais móveis (com $0,25 \mathrm{~m}^{2}$ ) para contagem de sementes dispersas, uma de cada lado da linha-base (Figura 1).

Os frutos encontrados nessas amostras foram coletados e colocados dentro de sacos de papel, onde se anotaram a direção correspondente, a distância do tronco e o número de frutos amostrados. A coleta de sementes, por ponto amostral, foi refeita até que fossem repetidas três amostras consecutivas sem frutos.

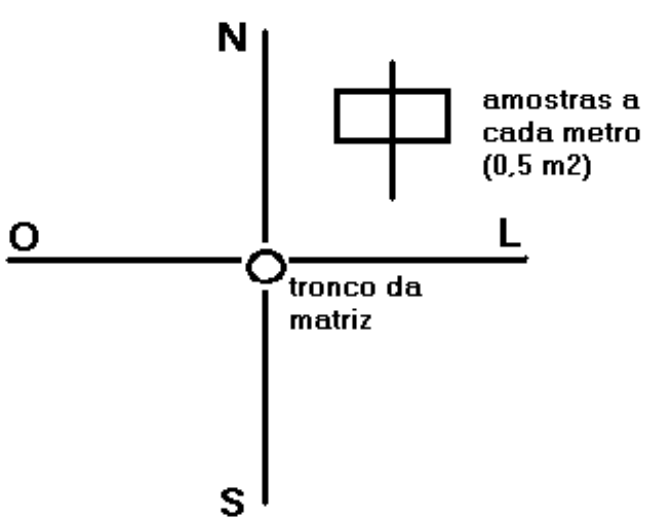

Figura 1 - Desenho esquemático do método utilizado para amostragem de sementes em cada matriz de Platypodium elegans Vog. escolhida para estudo na Estação Ecológica do Panga, Uberlândia, MG. $\mathrm{N}=$ norte, $\mathrm{S}=$ sul, $\mathrm{L}=$ leste e $\mathrm{O}=$ oeste.

Figure 1-Schematic design of the sample method of seed in each matrix of Platypodium elegans Vog. at Estação Ecológica do Panga, Uberlândia, MG. $N=$ North, $S=$ South, $L=$ east,$O=$ west.

Uma vez que alguns frutos apresentavam duas sementes desenvolvidas em seu interior, a unidade de dispersão considerada foi a semente, pois cada uma delas poderia resultar em novo indivíduo da espécie. Todos os frutos coletados foram abertos para verificar sinais de danos ou predação nas sementes e a possível causa. As coletas foram feitas semanalmente no período de agosto a novembro de 1998, durante o período de dispersão.

Os dados de dispersão analisados foram: a média do número de sementes coletadas em relação à distância da planta mãe; a proporção da média das sementes dispersadas sob a projeção da copa e fora desta; sementes intactas e danificadas dentro e fora da projeção da copa das matrizes; número de sementes dispersas em cada quadrante (coordenada), a partir do tronco das matrizes; e a probabilidade de estabelecimento das sementes pós-dispersão.

Foi utilizado o teste " $\mathrm{t}$ " para duas amostras independentes (ZAR, 1996) para comparar as diferenças ocorridas entre o número de sementes intactas e danificadas dentro e fora da projeção da copa. As diferenças no número de sementes dispersadas entre os quadrantes (norte, sul, leste e oeste) foram avaliadas por meio da ANOVA (ZAR, 1996). Todas as análises foram realizadas com o auxílio do programa SYSTAT, versão 10.2 (WILKINSON, 1990).

Revista Árvore, Viçosa-MG, v.34, n.5, p.807-813, 2010 


\section{RESULTADOS E DISCUSSÃO}

Foram amostradas 1.131 sementes, distribuídas nas cinco matrizes. O maior número de sementes foi encontrado próximo à planta-mãe, e decréscimo no número de sementes ocorreu com o aumento da distância da planta (Figura 2), confirmando a previsão de que a maioria das sementes é dispersa embaixo da copa da planta parental (JANZEN, 1970, 1971; HUBBELL, 1980). Isso pode ter ocorrido devido à redução da velocidade do vento provocada pela proximidade de outros indivíduos arbóreos de diversas espécies (FENNER, 1985). O mesmo foi verificado por Stiles (1989), quando afirmou que a interação entre o vento e a gravidade produz uma sombra de sementes, com a maioria das sementes depositadas abaixo do dossel das plantas parentais.

Nas florestas de Barro Colorado, a dispersão dos frutos de Platypodium elegans alcança uma distância de até $100 \mathrm{~m}$, sendo o “ótimo” para estabelecimento das plântulas entre 40 e 80 m (AUGSPURGER, 1984). Nesse mesmo estudo, a autora constatou que depois de um ano de dispersão dos frutos não ocorreu nenhum recrutamento embaixo ou perto da planta-mãe. Os indivíduos da EEP dispersam seus frutos a uma distância bem menor (em média $20 \mathrm{~m}$ ), o que pode ser explicado pela altura média dos indivíduos adultos dessa espécie na região (16 m contra $30 \mathrm{~m}$ do estudo citado). Assim,

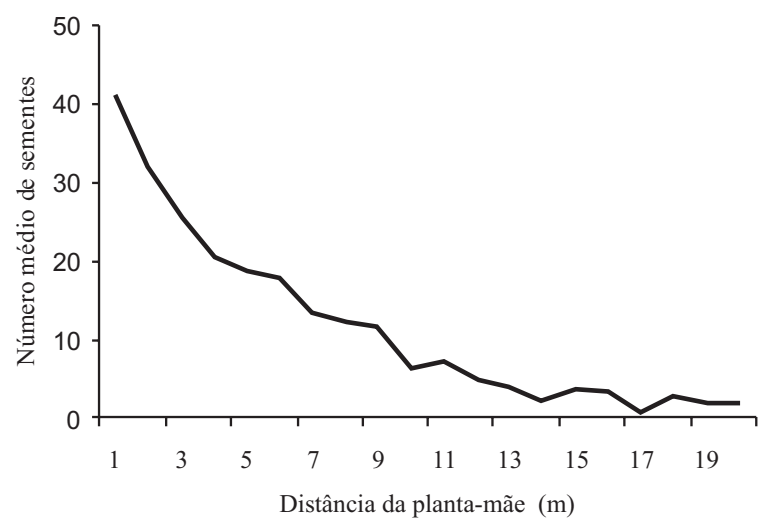

Figura 2 - Distribuição espacial da média de sementes de Platypodium elegans Vog. na Estação Ecológica do Panga, Uberlândia, MG. Coletas semanais no período de agosto a novembro de 1998.

Figure 2-Distribuition of number of seeds of the Platypodium elegans Vog. at Estação Ecológica do Panga, Uberlândia, MG. Weekly samplings in the period of August the November of 1998. as sombras de sementes geradas pelo vento são altamente variáveis de planta para planta e de ano para ano, e essas sombras dependem do tamanho da copa e da variação das condições do tempo (STILES, 1989). No entanto, a dispersão pelo vento é dependente de acontecimentos fortuitos, como redemoinhos ocasionais ou queimadas, que limpam a vegetação e possibilitam dispersão a distâncias maiores (COUTINHO, 1977).

As diferenças entre as matrizes amostradas na EPP e o estudo realizado em Barro Colorado (AUGSPURGER, 1984), quanto às distâncias das sementes amostradas a partir da planta-mãe, podem ter sido consequência das variações ambientais ou ocorrido devido a outros fatores, como a variabilidade genética entre as matrizes e,ou, diferenças fenológicas, como variações na quantidade de flores e frutos produzidos (MANTOVANI et al., 2003).

Apesar de ter sido observado decréscimo no número de sementes com o aumento da distância da plantamãe, a diferença entre o número de sementes dentro e fora da área de projeção da copa não foi significativa $\left(\mathrm{t}_{0,05}=0,311 ; \mathrm{p}=0,759 ; \mathrm{GL}=18\right)$ (Figura 3). Entretanto, houve diferença significativa entre o número de sementes danificadas e intactas dentro da projeção da copa $\left(\mathrm{t}_{0,05}=4,023 ; \mathrm{p}=0,004\right.$; e $\left.\mathrm{GL}=8\right)$ e fora da projeção da copa $\left(\mathrm{t}_{0,05}=4,338 ; \mathrm{p}=0,002 ; \mathrm{GL}=8\right)$ (Figura 3).

Seria esperada maior porcentagem de sementes intactas fora da área da copa das matrizes, devido à maior probabilidade de haver concentração de predadores onde ocorre maior concentração de sementes (JANZEN, 1970). Porém, quando comparadas apenas as sementes intactas dentro e fora da copa, não foi observada diferença significativa $\left(\mathrm{t}_{0,05}=0,844 ; \mathrm{p}=0,423\right.$; e $\left.\mathrm{GL}=8\right)$, o que pode ser explicado pelo maior número de sementes danificadas presentes na planta-mãe antes da dispersão. Das 1.131 sementes amostradas nas cinco matrizes, 208 (18,4\%) sementes estavam inteiras e potencialmente viáveis para germinar, enquanto 923 (81,6\%) sementes estavam aparentemente inviáveis (predadas, mofadas, malformadas e murchas). Dessa forma, as sementes inviáveis ainda na planta-mãe estariam sujeitas ao mesmo vetor da dispersão. De acordo com SOUZA et al. (2008), em espécies florestais nativas, como o Platipodium elegans, é comum a ocorrência de estruturas vazias e com sementes danificadas devido ao beneficiamento e,ou, ataque de insetos, além de apresentarem problemas como má-formação da semente. 


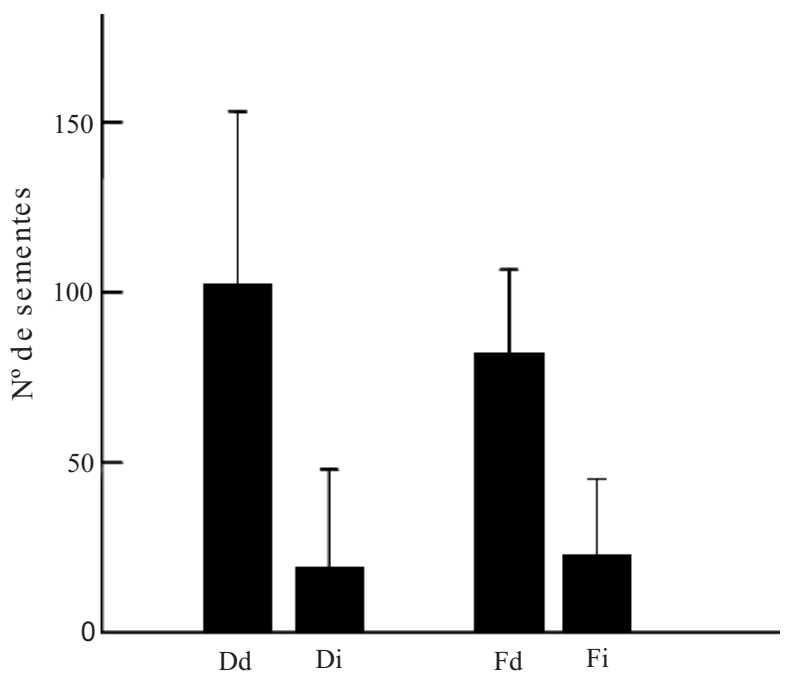

Figura 3 - Número de sementes (média + desvio-padrão) de Platipodium elegans dentro e fora da projeção da copa das matrizes localizadas na Estação Ecológica do Panga, Uberlândia, MG. Dd = sementes danificadas dentro da projeção da copa, $\mathrm{Di}=$ sementes intactas dentro da projeção da copa, $\mathrm{Fd}=$ sementes danificadas fora da projeção da copa e $\mathrm{Fi}$ = sementes intactas fora da projeção da copa.

Figure 3-Numbers of seeds (mean + SD) of Platypodium elegans inside and outside the projection of the crown of matrices located in the Estação Ecológica do Panga, Uberlândia, MG. Dd = seed damaged in the projection of the crown, $\mathrm{Di}=$ seed intact in the projection of the crown, Fd = seed damaged outside the projection of the crown, Fi = seeds intact outside the projection of the crown.

A dispersão das sementes de Platypodium elegans foi marginalmente significativa maior nas direções leste e norte, quando comparadas com oeste e sul (ANOVA, $\mathrm{F}_{3}=3,010, \mathrm{p}=0,06$; e GL = 16) (Figura 4). Entretanto, o maior número de sementes amostradas nessas direções (leste e norte) possivelmente se deva à topografia onde as matrizes estudadas estavam inseridas, associada a uma tendência no direcionamento do vento. As matrizes estavam localizadas em terreno com acentuado declive, o que favorecia o direcionamento das sementes para a mata de galeria adjacente e poderia contribuir com a composição florística e a distribuição dos propágulos que compõem o banco de sementes dessa fisionomia. Segundo Gasparino et al. (2006), os bancos de sementes são afetados tanto pelo tipo de dispersão das espécies presentes na área quanto por aqueles adotados pelas espécies de áreas adjacentes.
Desse modo, o banco de sementes é considerado um sistema dinâmico, cujo estoque acumulado é variável, de acordo com o balanço entre entradas e saídas. As entradas são provenientes da chuva de sementes que acontecem graças aos mecanismos atuantes de dispersão. As saídas, por sua vez, podem ocorrer por respostas fisiológicas, geneticamente controladas, ligadas a estímulos ambientais (luz, temperatura, umidade etc.) ou, ainda, através da morte, perda da viabilidade ou predação das sementes (GASPARINO et al, 2006). Nessa perspectiva, a probabilidade do estabelecimento de sementes pós-dispersão (balanço entre entrada e saída) de Platypodium elegans na EEP foi de 17\% do total da média de sementes amostradas.

Foram dispersas, em média, 227 sementes por matriz, e apenas $39(17 \%)$ puderam ser consideradas viáveis (sementes intactas) do total da média de sementes dispersadas inicialmente. Deste total, 40\% apresentavam algum tipo de dano que inviabilizava a germinação (sementes malformadas, murchos e estragados), ou predação nos frutos ainda jovens. Esta perda da viabilidade pode ter sido causada antes da dispersão, devido a respostas fisiológicas ou genéticas da planta. Os outros $43 \%$ das sementes foram predadas ou estavam mofadas após a dispersão. Essa alta porcentagem de sementes predadas ou mofadas que foram encontradas embaixo da copa das matrizes pode ser atribuída à presença de fungos, que aumentam sua proliferação de acordo com o aumento da densidade de sementes e a umidade, sendo esses dois fatores (predação e ação de fungos) com maior intensidade dentro da área da copa do que fora dela (AUGSPURGER, 1983).

O padrão de distribuição espacial de sementes encontrado, sendo o menor número de sementes amostradas tomado maiores distâncias da planta-mãe, sugere ser Platypodium elegans uma espécie de estabelecimento similar àquelas de floresta madura tropical. Entretanto, partindo do pressuposto de que a maior quantidade de sementes danificadas já estaria relacionada às respostas fisiológicas e genéticas à prédispersão, a semelhança entre a média de sementes intactas, tanto dentro como fora da projeção da copa, poderia estar assim sujeita aos mesmos facilitadores no processo de dispersão local, tendo em vista a interação propensa entre a gravidade e o direcionamento favorável do vento (norte e leste). Dessa forma, as matrizes selecionadas que se localizavam em terrenos com certo grau de declividade poderiam estar influenciando, por

Revista Árvore, Viçosa-MG, v.34, n.5, p.807-813, 2010 
sua vez, na direção da dispersão e, assim, no padrão de homogeneização da média de sementes amostradas intactas, independentes da projeção da copa.

Nessa perspectiva, o processo de dispersão estaria sofrendo influência de variações topográficas, respostas fisiológicas e genéticas à pré-dispersão, bem como pelo direcionamento favorável do vento. Assim, a atuação conjunta desses fatores estaria funcionando como facilitadores relevantes na formação do banco de sementes e moldariam a probabilidade de estabelecimento de novos indivíduos, tanto na área estudada quanto também nas fisionomias adjacentes.

\section{AGRADECIMENTOS}

A Noella Markstein e Cristiane Vilela de Freitas, pela colaboração na etapa de coleta de dados no campo; e a Vagner Santiago do Vale, pelas valiosas sugestões nas análises dos dados.

\section{REFERÊNCIAS}

ALMEIDA, S.P. de; PROENCA, C.E.B.; SANO, S.M.; RIBEIRO, J.F. Cerrado: espécies vegetais úteis. EMBRAPA-CPAC, Planaltina, DF, 1998.

AUGSPURGER, C.K. Seed dispersal of the tropical tree, Platypodium elegans, and the escape of its seedlings from fungal pathogens. Journal of Ecology, v. 71, p. 759-771, 1983.

AUGSPURGER, C.K. Seedling Survival of Tropical Tree species: Interactions of dispersal distance, light-gaps, and pathogens. Ecology, v. 65, n. 6, p. 1705-1712, 1984.

AUGSPURGER, C.K. Morphology and dispersal potential of wind-dispersed diaspores of Neotropical trees. Amererican Journal of Botany, v. 73, n. 3, p. 353-363, 1986.

AUGSPURGER, C.K.. Morphology and Aerodynamics of Wind-dispersed legumes. In: STIRTON, C.H.; ZARUCCHI, J.L. (eds.). Advances in Legume Biology. Monography Systematics Botanical Missouri Botanic Garden, v. 29, p. 451-466, 1989.

COUTINHO, L.M. Aspectos ecológicos do fogo no cerrado. II. As queimadas e a dispersão de sementes em algumas espécies anemocóricas do estrato herbáceo-subarbustivo. Boletim de Botânica da Universidade de São Paulo, v. 5, p. 57-64, 1977.
DAUBENMIRE, R.F. El factor atmosférico . In: Ecologia Vegetal: tratado de autoecologia de plantas. México. Ed. Limusa, S.A. 1982.

DREZNER, T.D., FALL, P.L.; STROMBERG, J.C. Plant distribuition and dispersal mechanisms at the Hassasyampa River Preserve, Arizona, USA. Global Ecology \& Biogeography, v. 10, p. 205-217, 2001.

FENNER, M., Seed Ecology. London. Ed. Chapman \& Hall. Cap. 3. p. 42. 1985.

FRANKIE, G.W.; BAKER, H.G.; OPLER, P.A..

Comparative phenolocial studies of trees in tropical wet and dry forest in the lowlands Costa Rica. Journal of Ecology, v. 62, p. 881-919, 1974.

GASPARINO, D.; MALAVASI, U.C.; MALAVASI, M.M.; SOUZA, I. Quantificação do banco de sementes sob diferentes usos do solo em área de domínio ciliar. Revista Árvore, v.30, n.1, p.1-9, 2006.

HARPER, J.L. The Population Biology of Plants. Academic Press. London, 1977.

HOWE, H.F.; SMALLWOOD, J. Ecology of seed dispersal. Annual Review of Ecology and Systematics, v. 13, p. 201-228, 1982.

HUBBELL, S.P. Seed predation and the coexistence of tree species in tropical forests. Oikos, v. 35, p. 214-229, 1980.

JANZEN, D.H. Herbivores and the number of tree species in tropical forests. The American Naturalist, v. 104, p. 501-528, 1970.

JANZEN, D.H. Association of a rain palm and seed-eating beetles in Puerto Rico. Ecology, v.53, p. 258-261, 1971.

JANZEN, D.H., 1988. Management of habitat fragments in a tropical dry forest: Growth. Ann. Missouri Bot. Gard. 75: 105-116.

KOPPEN, W. Climatologia: com um Estúdio de los Climas de la Terra. México, Fondo de Cultura Economica. 1948. 
LEVEY, D.J.; BYRNE, M.M. Complex ant-plant interactions: rain Forest ants as secundary dispersers and post-dispersal seed predators. Ecology, v. 74, n. 6, p. 1802-1812, 1993.

LORENZI, H., 2002. Árvores Brasileiras. $4^{\text {a }}$ ed. Plantarum. Nova Odessa, SP. 224p.

MANTOVANI, M.; RUSCHEL, A.R.; REIS, M.S.; PUCHALSKI, A.; NODARI, R.O. Fenologia reprodutiva de espécies arbóreas em uma formação secundária da floresta Atlântica. Revista Arvore, v. 27, n. 4, p. 451-458, 2003.

MORELLATO, L.P.C.; LEITÃO-FILHO, H.L.F. Padrões de frutificação e dispersão na Serra do Japi. In: MORELLATO, L.P.C. Cap. 7. História Natural da Serra do Japi: ecologia e preservação de uma área florestal no sudeste do Brasil. (L.P.C. MORELLATO org.). Ed. da Unicamp/ FAPESP. Campinas, SP. p.112, 1992.

MORELLATO, L.P.C.; RODRIGUES, R.R.; LEITAOFILHO, H.F.; JOLY, C.A. Estudo comparativo da Fenologia de espécies arbóreas de floresta de altitude e floresta mesófila semidecídua na Serra do Japi, Jundiaí, São Paulo. Revista Brasileira de Botânica, v. 12, p. 85-98, 1989.

RIBEIRO, J.F.; WALTER, B.M.T. Fitofisionômias do Bioma Cerrado. In: Cerrado Ambiente e Flora. SANO, S.M.; ALMEIDA, S.P. (eds.) EMBRAPA, Planaltina, DF. p. 89-166, 1998.

RIZZINI, C.T. Sobre as principais unidades de dispersão do Cerrado. In: III Simpósio sobre o Cerrado. Coordenador Ferri, M.G.. Ed. da Universidade de São Paulo. p. 117-133, 1971.
ROSA, R.; LIMA, S.C.C.; ASSUNÇÃO, W.L.

Abordagem preliminar das condições climáticas de Uberlândia (MG). Sociedade \& Natureza, v. 3, p. 91-108, 1991.

SCHIAVINI, I.; ARAÚJO, G.M. Considerações sobre a vegetação da Reserva Ecológica do Panga (Uberlândia). Sociedade \& Natureza, v.1, p. 61-66, 1989.

SCHORR, M.; SPONHOLZ, N.; PORTILHO, I. S. Desenvolvimento sustentável para o Vale do Ribeira. Planeta Orgânico, Trabalhos, 2002. Disponível em: http://

www.planetaorganico.com.br/TrabSchorr.htm. Acesso em: 10 fev. 2009.

SOUZA, L.A.; REIS, D.N.; SANTOS, J.P.; DAVIDE, A.C. Uso de raios-x na avaliação da qualidade de sementes de Platypodium elegans Vog. Rev. Ciênc. Agron., v. 39, n. 02, p. 343-347, 2008.

STILES, E.W. Fruits, seeds and dispersal agents. In: Plant Animal Interactions, ABRAHAMSON, WG.(ed.) Ed. McGraw-Hill Book Company, p.87-122, 1989.

VAN DER PIJL. Principles of Dispersal in Higher Plants. Springer-Verlag, New York. 2a ed, 161p, 1972.

ZAR, J.H. Biostatistical analysis. Prentice Hall, New Jersey, $3^{\text {a }}$ ed, 1996.

WILKINSON, L. SYSTAT: The System for Statistics. Systat Inc., Evanston, Illinois. 822p, 1990. 